\title{
Are elderly people living alone an at risk group?
}

Steve Iliffe, Sharon See Tai, Andrew Haines, Stephen Gallivan, Eva Goldenberg, Angela Booroff, Paula Morgan

\begin{abstract}
Objective-To test the hypothesis that elderly people living alone are an at risk group with a high level of morbidity that makes high demands on health and social services.

Design-Secondary analysis of data from a community survey of 239 people aged 75 and over, identified from general practitioners' age-sex registers.

Setting-Nine practices in the London boroughs
\end{abstract} of Brent and Islington.

Main outcome measures-Scores on the minimental state examination; stated satisfaction with life; assessment of mobility; numbers of diagnoses of major physical problems; numbers of prescribed drugs taken; urinary incontinence; alcohol consumption; contacts with general practitioners and hospital outpatient and inpatient services; contact with community health and social services.

Results-There were significantly more women among those living alone $(93 / 120(78 \%) v 63 / 119$ $(53 \%) ; p<0.0005)$ and the median age of elderly people living alone was higher $(81 v 80 ; p<0.04)$. Those living alone and those living with others showed no significant differences in measures of cognitive impairment, numbers of major physical diagnoses, impaired mobility, or use of general practitioner or hospital services. Stated satisfaction with life was somewhat higher in those living alone. Elderly people living alone were significantly more likely to have contact with chiropody, home help, and meals on wheels services and less likely to have someone they could contact in an emergency or at night. Living alone increased the likelihood of contact with one or more community health professionals (district nurses, health visitors, or chiropodists) considered as a group and also increased the likelihood of contact with social services as a whole. There was a tendency for more of those living alone than those living with others to have home visits from their general practitioners, but there were no significant differences in contact with hospital services between the two groups.

Conclusions-Elderly people living alone do not have an excess of morbidity compared with those living with others and do not seem to be an at risk group requiring specifically targeted assessments. More help is needed to provide elderly people living alone with a point of contact in case of emergency.

\section{Introduction}

General practitioners are now obliged to offer patients aged 75 and over annual domiciliary assessments to review their health and social circumstances. ${ }^{\prime}$ The idea that there are particular groups at risk amongst elderly people is appealing in a time of scarce resources and has face validity. Elderly people living alone have been described as an at risk group by the World Health Organisation, ${ }^{2}$ and the most recent report on assessment of elderly people published by the Royal College of General Practitioners describes elderly people living alone as a group that could be targeted for specific attention. ${ }^{3}$ Taylor and Ford identified elderly people living alone as an intermediate risk group, alongside the recently widowed, the poor, and those of unskilled manual worker background. The numbers of elderly people living alone in an area contribute to the underprivileged area (UPA (8)) index (Jarman score ${ }^{5}$ ), which measures perceived general practitioner workload and which is also used to weight general practitioner remuneration.

We used data from a predominantly white working class population of elderly people in North London to test the hypothesis that elderly people living alone are an at risk group.

\section{Methods}

General practitioners in nine practices in the London boroughs of Brent and Islington agreed to allow access to their age-sex registers, from which the names and addresses of all patients aged over 75 were extracted. These patients were asked by their general practitioner to take part in a study of the mental and physical health of elderly people and their use of medical and social services. All of those who agreed to participate ( 1160 ; response rate $90 \%$ ) were interviewed by trained non-medical fieldworkers using standard schedules. The general practices' medical records of all elderly patients participating were scrutinised by an experienced nurse coordinating the fieldwork, and all major diagnoses were recorded by using the ninth edition of the International Classification of Diseases (ICD-9). Since the purpose of the study was not primarily directed at the hypothesis examined in this report it is unlikely that any systematic bias in retrieving information from medical records was introduced. The study was performed just before the imposition in 1990 of the new contract for general practitioners and is therefore free from the influence of annual assessments of this age group. None of the practices involved had introduced any form of systematic review of their elderly populations before the study period.

All participants had a brief interview that included the mini-mental state examination, ${ }^{6}$ and basic data about the presence of carer, marital status, household size, and occupation before retirement were collected. The mini-mental state examination has been extensively validated, is acceptable to patients, and is judged to be an effective screening instrument for cognitive impairment. ${ }^{>}$Those scoring below 20 were recorded as showing probable cognitive impairment and those scoring 20-24 as showing probable cognitive impairment. Social class was derived from previous occupation according to the registrar general's classification. 
All participants were asked if they had a working telephone, if any neighbour had their front door key, whether they felt they could contact someone in an emergency, and whether they could get help at night.

A random sample of one in five patients was selected with random number tables from the whole population of people 75 and over registered with the nine practices, and 241 individuals were given a fuller interview. This included questions about the person's actual and potential support network; observation of mobility inside and report of mobility outside the home; details of recent contacts with medical services; a review of current prescribed drugs; details of current use of health and personal social services; and questions about urinary incontinence. Contact with general practitioners was investigated by asking if the subject had seen the general practitioner in the last three months, if the consultation had been at home or in the surgery, and who had initiated the consultation. Contact with hospital services was studied by asking if the subject had attended an outpatient clinic, or had been an inpatient, in the previous year. Satisfaction with life in general was assessed on a three point scale $(1=$ good, 2 =fair, 3 =poor). Information about alcohol consumption in the previous three months was assessed with a modified version of an interview schedule, the health survey questionnaire, previously used in community studies in the United Kingdom. ${ }^{\vee}$

Results were coded and entered on an SAS database and subsequently analysed with Minitab and SPSSPC. $\chi^{2}$, Fisher exact, and Mann-Whitney U tests were used where appropriate, and logistic regression analyses were used to examine the influence of living alone on use of services and to calculate odds ratios and odds ratios adjusted for age and sex according to standard methods. The $95 \%$ confidence intervals for percentage differences in values were calculated as

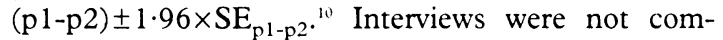
pleted with two individuals, so results are presented for 239 subjects.

TABLE I-Demographic characteristics of elderly people living alone or with other

\begin{tabular}{|c|c|c|c|c|}
\hline . & $\begin{array}{l}\text { No }(\%) \text { living } \\
\text { alone }(n=120)\end{array}$ & $\begin{array}{l}\text { No }(\%) \text { living with } \\
\text { others }(n=119)\end{array}$ & $\begin{array}{c}\% \text { Difference } \\
(95 \% \text { confidence interval })\end{array}$ & p Value ${ }^{\star}$ \\
\hline \multicolumn{5}{|l|}{ Sex: } \\
\hline Men & $27(23)$ & $56(47)$ & $-24 \cdot 5(-36 \cdot 2$ to $-12 \cdot 9)$ & \multirow[t]{2}{*}{$<0.0005$} \\
\hline Women & $93(78)$ & $63(53)$ & $24.5(12.9$ to 36.2$)$ & \\
\hline \multicolumn{5}{|l|}{ Age: } \\
\hline $75-79$ & $44(37)$ & $59(50)$ & $-12.9(-25 \cdot 4$ to -0.5$)$ & \multirow{2}{*}{$<0.05$} \\
\hline$\geqslant 80$ & $76(63)$ & $60(50)$ & $12.9(0.5$ to 25.4$)$ & \\
\hline \multicolumn{5}{|l|}{ Civil status: $†$} \\
\hline Widowed & $90(75)$ & $33(28)$ & $47.3(0.5$ to 16.3$)$ & \multirow[t]{4}{*}{$<0.00001$} \\
\hline Married & & $74(63)$ & $-62 \cdot 2(-70 \cdot 9$ to $-53 \cdot 5)$ & \\
\hline Single & $18(15)$ & $8(7)$ & $8 \cdot 3(36 \cdot 8$ to $59 \cdot 0)$ & \\
\hline Divorced or separated & $11(9)$ & $4(3)$ & $5 \cdot 6(-0 \cdot 2$ to $12 \cdot 0)$ & \\
\hline
\end{tabular}

* $\chi$ : Test.

tData not recorded for one individual living alone.

TABLE II-Health indicators among elderly people

\begin{tabular}{|c|c|c|c|}
\hline & $\begin{array}{l}\text { No }(\%) \text { living } \\
\text { alone }(n=120)\end{array}$ & $\begin{array}{l}\text { No }(\%) \text { living with } \\
\text { others }(n=119)\end{array}$ & $\begin{array}{c}\% \text { Difference } \\
\text { (95\% confidence interval) }\end{array}$ \\
\hline \multicolumn{4}{|l|}{ Cognitive impairment score: } \\
\hline $0-19$ (cognitively impaired) & $4(3)$ & $8(7)$ & $-3 \cdot 5(-9 \cdot 1$ to $2 \cdot 1)$ \\
\hline $20-24$ (possibly impaired) & $9(8)$ & $15(13)$ & $-5 \cdot 3(-13$ to $2 \cdot 4)$ \\
\hline$\geqslant 25$ & $107(89)$ & $94(79)$ & $8.9(-0.3$ to 17.9$)$ \\
\hline \multicolumn{4}{|l|}{ Mobility: } \\
\hline Fully mobile & $60(50)$ & $67(56)$ & $-7.3(-19.9$ to $5 \cdot 4)$ \\
\hline Slightly impaired & $28(23)$ & $26(22)$ & $1.1(-9.6$ to 11.8$)$ \\
\hline Moderately impaired & $31(26)$ & $22(18)$ & $7.0(-3.5$ to 17.6$)$ \\
\hline Bed or wheelchair bound & $1(1)$ & $2(2)$ & $-0.9(-3.7$ to 2.0$)$ \\
\hline \multicolumn{4}{|l|}{ No of major diagnoses: } \\
\hline None & $28(24)$ & $20(17)$ & $6.7(-3.5$ to 17.0$)$ \\
\hline $1-2$ & $73(61)$ & $87(73)$ & $-11 \cdot 8(-23 \cdot 7$ to -0.03$)$ \\
\hline$\geqslant 3$ & $17(14)$ & $11(9)$ & $5 \cdot 1(-3 \cdot 1$ to $13 \cdot 3)$ \\
\hline \multicolumn{4}{|l|}{ No prescribed drugs: } \\
\hline None & $34(28)$ & $45(38)$ & $-9.9(-21.9$ to 2.1$)$ \\
\hline $1-3$ & $65(54)$ & $54(45)$ & $8 \cdot 4(-4 \cdot 2$ to $21 \cdot 2)$ \\
\hline$\geqslant 4$ & $20(17)$ & $18(15)$ & $1.4(-8.0$ to 10.8$)$ \\
\hline Urinary incontinence & $27(23)$ & $17(14)$ & $8.4(-1.7$ to 18.5$)$ \\
\hline
\end{tabular}

\section{Results}

Data analysis was performed with the complete random sample and repeated leaving out those with probable cognitive impairment (mini-mental state examination score 0-19) and possible cognitive impairment (scores 20-24) to exclude potentially inaccurate answers given by individuals with dementia. There were no differences in results between the whole random sample and the random sample that excluded cognitively impaired patients, and so results for the whole random sample are given here. Differences in totals for some analyses reflect incomplete data collection.

Table I shows the basic demographic features of those living alone and those living with others. The median age of those living alone was 81 , significantly higher than the 80 year median age of those living with others (Mann-Whitney $U$ test, $p<0.04$ ). There was no significant difference in the social class backgrounds of the two populations.

Those living alone were slightly less likely to have living children than those living with others $(77$ (64\%) $v 90(76 \%))$ and also less likely to have living siblings $(74(63 \%) v 88(74 \%))$. Telephones were present in the homes of $102(85 \%)$ of those living alone and of 104 $(87 \%)$ of those living with others. Front door keys were left with neighbours by $95(79 \%)$ of those living alone and by $88(74 \%)$ of those living with others. Thirty one $(26 \%)$ of those living alone and seven $(6 \%)$ of those living with others felt that they had no one they could contact in an emergency $\left(\chi^{2}=17.84, p<0.001\right)$. The perceived availability of help at night also differed significantly between the two groups, with $37(31 \%)$ of those living alone and $13(11 \%)$ of those living with others reporting no source of night time assistance $\left(\chi^{2}=14 \cdot 10, \mathrm{p}<0 \cdot 001\right)$

No significant differences were observed in the prevalence of scores suggesting cognitive impairment between the two groups (table II). The rise in the prevalence of cognitive impairment with age in this population has been documented elsewhere, as has the lack of significant difference in the sex distribution of cognitive impairment." No significant differences were found between those living alone and not alone in the numbers of major physical diagnoses, the numbers of prescribed drugs taken, the prevalence of impaired mobility, and the prevalence of incontinence.

Analysis of these data for men and women separately showed no significant differences within the sexes between those living alone and not alone, for any of the preceding factors. Women living alone were significantly more likely to take several medicines than were men living alone $\left(37 / 92(40 \%) v 3 / 27(11 \%), \chi^{2}=11 \cdot 18\right.$, $\mathrm{p}<0.001)$, but there was no significant difference in numbers of drugs used between the men and women living with others. Urinary incontinence was significantly more common among women than men in the group living with others $(13 / 59(22 \%) v 4 / 55(7 \%)$, $\left.\chi^{2}=4 \cdot 88, \mathrm{p}<0 \cdot 05\right)$, but there was no significant difference in the prevalence of incontinence between men and women living alone, or between all those living alone and those not living alone, and adjustment for both age and sex with logistic regression analysis did not alter this. The unadjusted odds ratio for those living alone was $1.7(95 \%$ confidence interval 0.9 to $3.4 ; \mathrm{p}>0.1)$; after adjustment for age and sex the odds ratio was $1.4(0.7$ to $2.9 ; \mathrm{p}>0.3)$.

Satisfaction with life in general was significantly greater among those living alone than among those living with others. Forty four of those living alone $(37 \%)$ compared with 28 of those living with others $(24 \%)$ described their level of satisfaction as good $\left(\chi^{2}=4.54, \mathrm{p}<0.05\right)$. No member of either group described their level of satisfaction as poor. Reported alcohol consumption did not vary significantly between 
worker contacts, and day centre or luncheon club

\begin{tabular}{|c|c|c|c|}
\hline & $\begin{array}{l}\text { No ("/o) living } \\
\text { alone }(\mathrm{n}=120)\end{array}$ & $\begin{array}{l}\text { No }(\%) \text { living with } \\
\text { others }(n=119)\end{array}$ & $\begin{array}{c}\% \text { Difference } \\
(95 \% \text { confidence interval })\end{array}$ \\
\hline \multicolumn{4}{|l|}{ Individual services: } \\
\hline \multicolumn{4}{|l|}{ General practitioner contact: } \\
\hline Surgery ${ }^{\star}$ & $58(48 \cdot 3)$ & $54(45 \cdot 4)$ & $2.9(-9.7$ to 15.6$)$ \\
\hline Home $^{\star}$ & $22(18 \cdot 3)$ & $11(9 \cdot 2)$ & $9 \cdot 1(0 \cdot 4$ to $17 \cdot 8)$ \\
\hline Outpatient attendance & $61(51 \cdot 7)$ & $63(54 \cdot 8)$ & $-3 \cdot 1(-15 \cdot 9$ to $9 \cdot 7)$ \\
\hline \multirow{2}{*}{\multicolumn{4}{|c|}{$\begin{array}{l}\text { Hospital aamission } \\
\text { Communty health services: }\end{array}$}} \\
\hline & & & \\
\hline Chiropody & $48(40 \cdot 3)$ & $32(27 \cdot 6)$ & $12.7(0 \cdot 8$ to $24 \cdot 7)$ \\
\hline Day hospital & & $1(0.9)$ & $-0.9(-2.5$ to 0.8$)$ \\
\hline Health visitor & $9(7 \cdot 6)$ & $3(2 \cdot 6)$ & $5 \cdot 0(-0.6$ to $10 \cdot 5)$ \\
\hline District nurse & $18(15 \cdot 1)$ & $10(8 \cdot 6)$ & $6.5(-1.7$ to 14.7$)$ \\
\hline \multicolumn{4}{|l|}{ Social services: } \\
\hline Social worker & $10(8 \cdot 4)$ & $6(5 \cdot 2)$ & $3 \cdot 2(-3 \cdot 2$ to $9 \cdot 6)$ \\
\hline Day centre & $3(2.5)$ & & $2.5(-0.3$ to 5.3$)$ \\
\hline Home help & $46(38.7)$ & $17(14 \cdot 7)$ & $24.0(13.1$ to 34.9$)$ \\
\hline Meals on wheels & $16(13.5)$ & $6(5 \cdot 2)$ & $8.3(0.9$ to $15 \cdot 6)$ \\
\hline Luncheon club & $11(9 \cdot 2)$ & $6(5 \cdot 2)$ & $4 \cdot 0(-2 \cdot 6$ to $10 \cdot 6)$ \\
\hline \multicolumn{4}{|l|}{ Aggregated services: } \\
\hline \multicolumn{4}{|l|}{ Total general practitioner } \\
\hline contact & $81(68 \cdot 6)$ & $66(57.9)$ & $10 \cdot 7(-1.6$ to $23 \cdot 1)$ \\
\hline Community health services & $59(49 \cdot 6)$ & $38(32 \cdot 8)$ & $16 \cdot 8(4 \cdot 4$ to $29 \cdot 2)$ \\
\hline Social services & $51(42.9)$ & $26(22 \cdot 4)$ & $20.5(8.8$ to 32.1$)$ \\
\hline
\end{tabular}

*Percentages are of all those living alone or not alone, not just of those who reported a consultation with their general practitioner in the previous three months.

TABLE IV-Odds ratios for use of services among elderly people living alone

\begin{tabular}{|c|c|c|c|c|}
\hline & $\begin{array}{l}\text { Unadjusted odds ratio } \\
\text { (95\% confidence interval) }\end{array}$ & $\mathrm{p}$ Value & $\begin{array}{c}\text { Adjusted odds ratio }{ }^{\star} \\
(95 \% \text { confidence interval) }\end{array}$ & $\mathrm{p}$ Value \\
\hline \multicolumn{5}{|l|}{ Individual services: } \\
\hline General practioner's home visits. & $1.9(0.8$ to 4.2$)$ & $<0.2$ & $1.7(0.7$ to 3.9$)$ & $<0.3$ \\
\hline Outpatient visit & $0.9(0.5$ to 1.5$)$ & $<0.7$ & $0.9(0.5$ to 1.5$)$ & $<0.6$ \\
\hline Inpatient care & $1.3(0.7$ to 2.3$)$ & $<0.5$ & $1.4(0.7$ to 2.6$)$ & $<0.4$ \\
\hline Chiropody & $1.8(1.0$ to $3 \cdot 1)$ & $<0.05$ & $1.7(1.0$ to $3 \cdot 1)$ & $<0.07$ \\
\hline Home help & $3.7(1.9$ to 6.9$)$ & $<0.0002$ & $3 \cdot 2(1 \cdot 6$ to $6 \cdot 2)$ & $<0.0007$ \\
\hline Meals on wheels & $2 \cdot 8(1 \cdot 1$ to $7 \cdot 6)$ & $<0.04$ & $2.6(0.9$ to $7 \cdot 4)$ & $<0.07$ \\
\hline \multicolumn{5}{|l|}{ Aggregated services: } \\
\hline Total general practitioner contact & $1.6(0 \cdot 9$ to $2 \cdot 7)$ & $<0 \cdot 1$ & $1.6(0.9$ to 2.7$)$ & $<0.2$ \\
\hline Community health services & $2 \cdot 0(1 \cdot 2$ to $3 \cdot 1)$ & $<0.01$ & $1.9(1.1$ to $3 \cdot 3)$ & $<0.03$ \\
\hline Social services & $2.6(1.5$ to 4.6$)$ & $<0.002$ & $2 \cdot 3(1 \cdot 3$ to $4 \cdot 2)$ & $<0.007$ \\
\hline
\end{tabular}

*Adjusted for age and sex.

†Home visits versus surgery contact.

the populations, with 36 regular drinkers (30\%) among those living alone and 40 drinkers (34\%) among those living with others.

Those living alone were not significantly more likely to have had contact with their general practitioner in the previous three months or to have been hospital outpatients or inpatients in the previous year. Those living alone tended to be more likely to have home visits from their general practitioners $(p>0.05)$. The proportions of consultations initiated by general practitioners in the two groups were not significantly different. Seventeen of those living alone $(21 \%)$ reported that their doctor had initiated consultations in the previous three months, compared with 11 of those living with others $(17 \%)$. There was a significant difference in the range of services received by those living alone compared with those living with others (tables III and IV).

Logistic regression analysis, using contact with different services as the dependent variable, was used to explore the relation between service use and lone status. Odds ratios, unadjusted and adjusted for age and sex, are shown in table IV.

Logistic regression analyses were not performed separately for contacts with health visitors, district nurses, social workers, day centres, and hospitals and luncheon clubs because of the small numbers of people in contact with these services, but analyses were performed for two aggregated categories of service use. Grouping contacts with chiropodists, district nurses, health visitors, and day hospital care together as "community health services" and using this as a dependent variable in logistic regression analysis showed that living alone significantly increased the likelihood of receiving community health services even when age and sex were taken into account. A similar analysis using home help, meals on wheels and social attendance as "social services" showed that those living alone had a significantly greater likelihood of receiving social services, even after sex and age were adjusted for.

\section{Discussion}

The proportion of elderly people living alone in this survey is higher than the national figure of $40 \%,{ }^{12}$ no doubt because the population studied lived in inner city areas. Since the elderly people living alone in this study were significantly older, with a higher proportion of women, than those living with others, they would be expected to have somewhat higher levels of morbidity and use of services. However, elderly people living alone showed no significant characteristics that suggest that they are a group strongly at risk. Although we cannot show that elderly people living alone are healthier than those living with others, as Power did, ${ }^{13}$ we found that use of general practitioner and hospital services was not significantly different between the two populations, and we could find no difference in the numbers of important medical problems, the numbers of prescribed drugs used, and the extent of impaired mobility. Although the questions used on quality of life were very simple, the answers given by those living alone did not suggest that they perceive themselves as worse off than those living with others.

Elderly people living alone did have significantly greater contact with some community services, although adjustment for age and sex weakened this. The higher levels of support given by community health and social services to those living alone, together with the lack of evidence of increased morbidity within this group, suggests that services are standing in for family support or care by neighbours rather than responding to specific physical needs, a finding consistent with other studies. ${ }^{1+10}$

\section{GENERAL. PRACTITIONER WORKLOAD}

Although initial organisation of such care and subsequent liaison with health and community care workers may increase general practitioner workload, these data do not provide strong evidence that general practitioners have substantially greater overall workload as a consequence of caring for elderly people living alone rather than for those living with others. The trend for elderly people living alone to have more contacts with their general practitioners was not statistically significant. Although a type II error is possible, the sample size in this study gives a greater than $80 \%$ power of picking up a difference of $50 \%$ and $70 \%$ at $5 \%$ probability in the proportions of each group consulting their general practitioners within a three month period (that is, an odds ratio of 2.33).

Our study suggests that in most respects patterns of morbidity and the use of primary care services by elderly people living alone are similar to those of elderly people living with others. There are some differences in that elderly people living alone seem to require more home visits and make more use of community services. Both of these factors will add to general practitioners' workload, although this is difficult to quantify. This study population is equivalent to the elderly population of an "average" practice of two doctors with a combined list size of 4000 . Elderly people aged 75 and over account for only about $10 \%$ of consultations in general practice, ${ }^{12}$ so practices would have to differ appreciably in the proportion of elderly people living alone for this to have a perceptible impact on overall workload at the level of the individual doctor. Although it is not possible to say from our data that the use of elderly people living alone in the UPA(8) deprivation score is entirely unjustified, it does seem to 
be questionable. A larger study, specifically designed to test the hypothesis that elderly people living alone make greater use of general practitioner services, would be needed to confirm or refute our view.

DEPRIVATION INDEX

The proportion of elderly people living alone is one of the eight factors in the deprivation index used to weight general practitioners' remuneration. ${ }^{5}$ When general practitioners in the study from which the deprivation index was derived were asked to rank the factors they perceived as increasing their workload on a range from 0 to 9 , elderly people living alone received the highest weighting: $6 \cdot 62 . .^{7}$ The magnitude of this weighting is not consistent with our findings, even allowing for the possibility that in some practices elderly people living alone would make a measurable difference to workload. The inability of general practitioners to know whether elderly people living alone consult disproportionately to their numbers on the list has been commented on before. ${ }^{18}$

In the original study of general practitioners' perceptions of factors affecting their workload, elderly people were defined as those aged 65 and over; we have studied only those aged 75 and over. This is unlikely to alter our conclusions, however, since the 65-74 age group has a lower consultation rate than the group aged 75 and over and a lower prevalence of acute and chronic health problems. ${ }^{14}$

\section{A VULNERABLE GROUP?}

The belief that elderly people living alone are particularly vulnerable or needy may have a historic basis $^{20}$ that has been superseded by improvements in health, in living standards, and in the development of community services, even in a relatively deprived population such as the one we have studied. For example, earlier studies had shown that elderly people living alone were less likely to have access to a telephone and to be less able to obtain help in an emergency. ${ }^{21}$ In our study about $15 \%$ of subjects had no working telephone, and about one in five did not have neighbours who could gain access to their homes if needed. This may mean that some people are still potentially isolated at times of need, but the proportion of the population in this situation is much less than the two thirds of elderly people living alone without telephones noted by Hunt in $1978 .{ }^{21}$ Nevertheless, one quarter of those living alone perceived themselves as being without someone whom they could contact in an emergency, and nearly a third felt that they could not get help at night, suggesting the need for help to provide a point of contact for elderly people in case of emergency.

Being alone may be mistaken for being isolated or be associated with being lonely, even though there is ample evidence that isolation and loneliness can occur within families and that elderly people living alone can have extensive social networks. ${ }^{22}$ Alternatively, the belief in the particular vulnerability of elderly people living alone may be a variant of the view that elderly people are a problem, and that those needing outside support in times of illness are a particular problem. Such views are typical of the professional paradigm of old age, in which contact with elderly people at risk and in great need biases professionals' perceptions of the whole elderly population, which becomes stereotyped as frail and actually or potentially dependent. ${ }^{23}$

\section{IMPLICATIONS FOR SOCIAL POLICY}

The increasing number of elderly people living alone can be seen as an advance for social policy, in that more are retaining their independence for longer. ${ }^{22}$ As Taylor and Ford point out, although at risk groups may contain a higher proportion of people with problems, there are still more "cases" outside the at risk group than in it, and at risk groups make a poor basis for a screening programme among the elderly. ${ }^{24}$ On the basis of our findings, identification of elderly people living alone as an at risk group worthy of focused attention as suggested both in a publication of the World Health Organisation ${ }^{2}$ and in a recent paper published by the Royal College of General Practitioners, ${ }^{3}$ seems unjustified. Similarly, weighting general practitioner remuneration according to a formula that includes the numbers of elderly people living alone in the local population ${ }^{5}$ may not be appropriate and would require more rigorous testing than it has had if the proportion of elderly people living alone is to be incorporated into a second generation "workload" index. However, financial weighting for the elderly alone seems to be justified for local authority social services and perhaps for selected community health services.

Professor Anthony Mann and Enid Levin assisted us with interviewer training and advised on appropriate screening instruments. The research was funded by the Mental Health Foundation, and SI was funded by a Royal College of General Practitioners research fellowship. We are grateful for the help given by doctors and staff in practices that participated in this study. Staff at the Rayne Institute computer unit contributed to the data analysis, and Aliya Osman and Sheila Foreman assisted with data collection.

1 Department of Health. A new contract for general practice. London: HMSO, 1990.

2 World Health Organisation. Prevention of mental disorders in the elderly. Copenhagen: WHO, 1977

3 Royal College of General Practitioners. Care of old people: a framework for progress. London: RCGP, 1990. (Occasional paper 45.)

4 Taylor RC, Ford G. The elderly at risk: a critical examination of commonly identified risk groups. I R Coll Gen Pract 1983;33:699-705.

5 Jarman B. Identification of underprivileged areas. $B M F$ 1983;286:1705-9.

6 Folstein MF, Folstein SE, McHugh PR. The mini-mental state-a practical method for grading the cognitive state of patients for the clinician. $\mathcal{I}$ Psych method for grading

7 O'Connor DW, Politt JB, Hyde JB, et al. Continuing clinical validation of dementia diagnosed in the community using the Cambridge menta disorders of the elderly examination. Acta Psychiatr Scand 1991;83:41-5.

8 Wallace PG, Cutler S, Haines AP. The use of a questionnaire in genera practice to increase the recognition of patients with excessive alcoho consumption. Alcohol Alcohol 1985;290:1949-53.

9 Altman DG. Practical statistics for medical research. London: Chapman Hall, 1991

10 Armitage P, Berry G. Statistical methods in medical research. Oxford: Blackwell Scientific, 1991

11 Iliffe S, Booroff A, Gallivan S. Screening for cognitive impairment in the elderly using the mini-mental state examination. Br f Gen Pract 1990;40: $277-9$.

12 Office of Population Consensus and Surveys. General household survey. London: HMSO, 1989.

13 Power $M$. The use of volunteers in the home care of the very old. London. London: DHSS, 1979:69.

14 Bebbington AC. Changes in the provision of social services to the elderly in the community over fourteen years. Sacial Policy and Administration 1980;13: $114-23$

15 Qureshi H, Walker A. Caring for elderly people: the family and the state. In Phillipson C, Walker A, eds. Ageing and social policy: a critical assessmen. Aldershot: Avebury, 1987

16 Levin E, Sinclair I, Gorbach P. Families, services and confusion in old age. Aldershot: Avebury, 1989

17 Jarman B. Social deprivation and health service funding. London: Imperial College of Science, Technology and Medicine, 1990. (Papers in science, technology, medicine and public policy No 22.)

18 Carr-Hill RA, Sheldon T. Designing a deprivation payment for general practitioners: the UPA(8) wonderland. BMF 1991;302:393-6.

19 Victor CR. Health and health care in later life. Milton Keynes: Open University Press, 1991.

20 Tunstall J. Old and alone. London: Routledge \& Kegan Paul, 1960.

21 Hunt A. The elderly at home. London: HMSO, 1978.

22 Tinker A. The elderly in modern society. Harlow: Longman, 1984

23 Perkins ER. Preventive care of the elderly: a literature review for the development of policy and practice. Nottingham: Health Promotion Unit, 1989.

24 Taylor R, Ford G. Functional geriatric screening: a critical review of curren developments. In: Taylor RC, Buckley EG. Preventive care of the elderly: review of current developments. London: Royal College of General Practitioners, 1987. (Occasional paper 35.)

(Accepted 8 September 1992) 